DEPARTMENT OF THE INTERIOR

UNITED STATES GEOLOGICAL SURVEY

\title{
BEDROCK GEOLOGIC MAP OF THE EAST KILLINGLY QUADRANGLE, CONNECTICUT AND RHODE ISLAND
}

By George E. Moore, Jr.

Prepared in cooperation with the STATE OF CONNECTICUT GEOLOGICAL AND NATURAL HISTORY SURVEY 


\section{GEOLOGIC MAP SYMBOLS}

COMMONLY USED ON MAPS OF THE UNITED STATES GEOLOGICAL SURVEY

(Special symbols are shown in explanation)

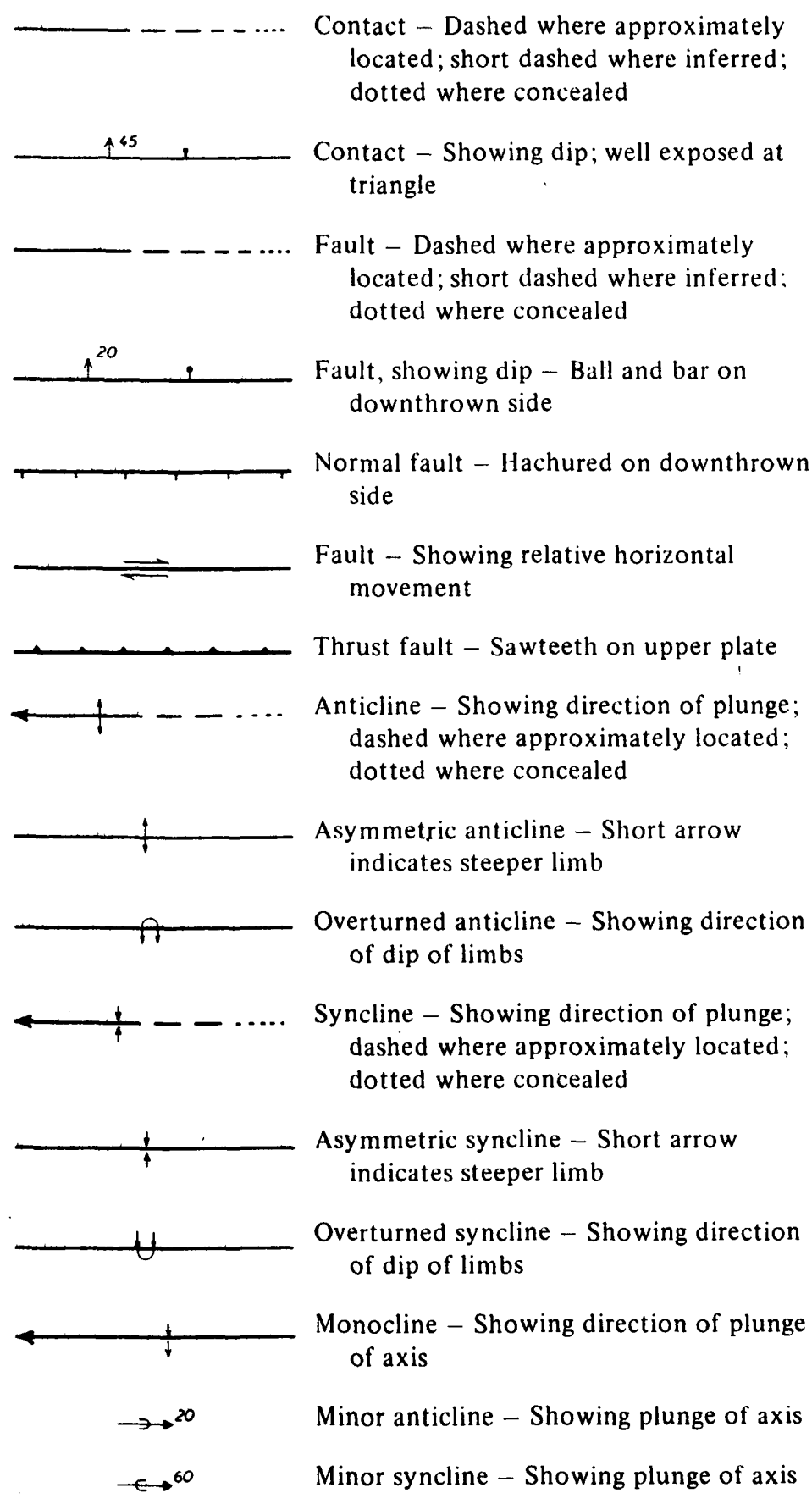

\author{
Strike and dip of beds - Ball indicates \\ top of beds known from sedimen- \\ tary structures \\ 70 Inclined $\oplus$ Horizontal
+ Vertical $\stackrel{40}{\longrightarrow}$ Overturned \\ Strike and dip of foliation \\ 20 Inclined $\rightarrow$ Vertical $\downarrow$ Horizontal \\ Strike and dip of cleavage \\ $\stackrel{15}{ }$ Inclined $\longmapsto$ Vertical If Horizontal \\ Bearing and plunge of lineation \\ $15 \longleftarrow$ Inclined $\bullet$ Vertical $\longleftrightarrow$ Ilorizontal \\ Strike and dip of joints \\ 4 $^{40}$ Inclined $\rightarrow$ Vertical $\rightarrow$ Horizontal \\ Note: planar symbols (strike and dip of beds, \\ foliation or schistosity, and cleavage) may be \\ combined with linear symbols to record data \\ observed at same locality by superimposed \\ symbols at point of observation. Coexisting \\ planar symbols are shown intersecting at point \\ of observation.
}

Shafts

๑ Vertical $\$$ Inclined

Adit, tunnel, or slope

¿Accessible $\nsim$ Inaccessible

x. Prospect

Quarry

\& Active $\&$ Abandoned

Gravel pit

$x$ Active

* Abandoned

Oil well

- Drilling $\phi$ Shut-in $\phi$ Dry hole

Cas Show of gas abandoned

- Oil Show of oil 